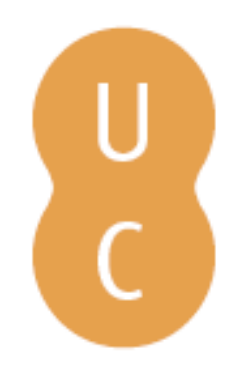

\title{
nombalina
}

\section{Biblioteconomia ou Ciência da Informação?}

Autor(es): $\quad$ Arruda, Maria Izabel Moreira

Publicado por: Imprensa da Universidade de Coimbra

URL persistente:

URI:http://hdl.handle.net/10316.2/31852

DOI:

DOI:http://dx.doi.org/10.14195/978-989-26-0319-3_4

Accessed : $\quad$ 26-Apr-2023 07:24:51

A navegação consulta e descarregamento dos títulos inseridos nas Bibliotecas Digitais UC Digitalis, UC Pombalina e UC Impactum, pressupõem a aceitação plena e sem reservas dos Termos e Condições de Uso destas Bibliotecas Digitais, disponíveis em https://digitalis.uc.pt/pt-pt/termos.

Conforme exposto nos referidos Termos e Condições de Uso, o descarregamento de títulos de acesso restrito requer uma licença válida de autorização devendo o utilizador aceder ao(s) documento(s) a partir de um endereço de IP da instituição detentora da supramencionada licença.

Ao utilizador é apenas permitido o descarregamento para uso pessoal, pelo que o emprego do(s) título(s) descarregado(s) para outro fim, designadamente comercial, carece de autorização do respetivo autor ou editor da obra.

Na medida em que todas as obras da UC Digitalis se encontram protegidas pelo Código do Direito de Autor e Direitos Conexos e demais legislação aplicável, toda a cópia, parcial ou total, deste documento, nos casos em que é legalmente admitida, deverá conter ou fazer-se acompanhar por este aviso. 
Maria Manuel Borges

Elias Sanz Casado

Coordenação

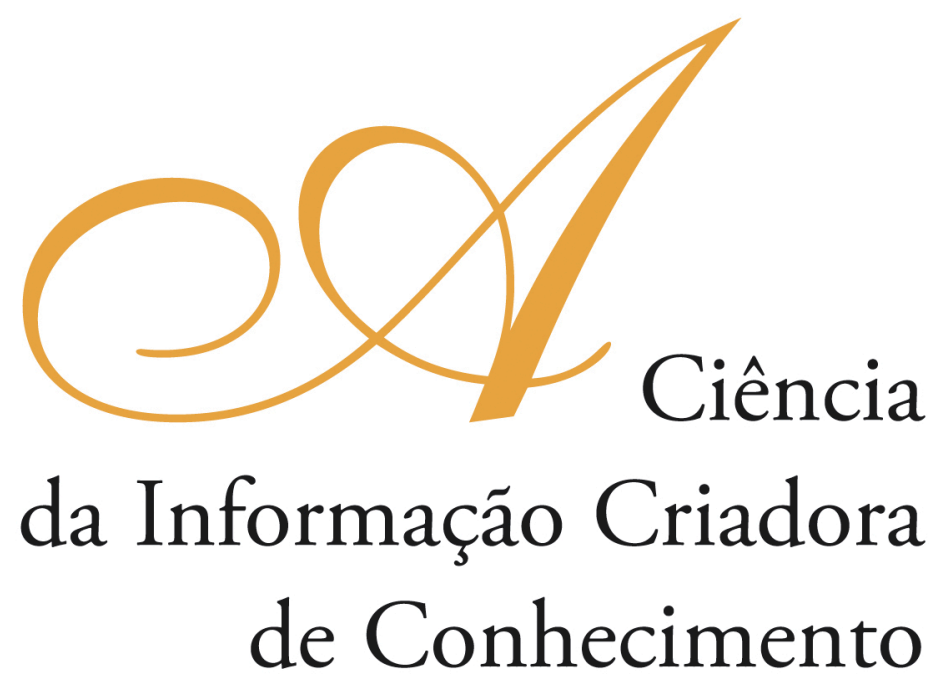

Vol. I

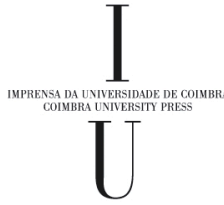

- COIMBRA 2009 


\title{
Biblioteconomia ou Cî̂nCia da Informação?
}

\author{
Maria Izabel Moreira Arruda \\ Universidade Federal do Pará (Brasil)
}

\section{Resumo}

As mudanças ocorridas no mundo atual interferem na Biblioteconomia, ocasionando dinamismo na profissão do bibliotecário, e o surgimento da Ciência da Informaçâo promove o arcabouço teórico para o estudo da informação, possibilitando a relação da prática com a teoria. A informaçáo, que no passado circulava oralmente ou na forma de livros, apresenta-se agora em suportes diversos, tanto impressos quanto eletrônicos, sob forma de livros ainda, mas também como periódicos, papers, fitas de vídeo, CD-ROM, DVD, entre outros, e o bibliotecário exercita-se entre a informação e seu usuário, facilitando-lhe a localização, garantindo-lhe o acesso e promovendo o seu uso. Os usuários das bibliotecas e dos sistemas de informação atuais diferem dos leitores das bibliotecas de alguns anos atrás, especialmente no que concerne ao fator tempo: se no passado, o leitor freqüentava a biblioteca para ler por horas seguidas, no presente o usuário demanda a informaçáo para ler em outros ambientes. No estudo da Ciência da Informação, desde a década de 1940, muitos estudiosos se destacam como Vannevar Bush, Calvin Mooers, Mikhailov, Borko, Saracevic, Wersig, entre outros. A Ciência da Informação dedica-se às questôes científicas e à prática profissional voltadas para os problemas da efetiva comunicaçáo do conhecimento e de seus registros entre os seres humanos, no contexto social, institucional ou individual do uso e das necessidades de informaçáo. Para esses estudos, as tecnologias de informação são essenciais. A Biblioteconomia envolve desde o estudo do perfil do usuário, desenvolvimento de coleções, até a promoção do uso da informaçáo, abrangendo um longo caminho a ser percorrido pelo bibliotecário. Enfim, Ciência da Informação, Biblioteconomia e demais correntes científicas que têm como objeto de estudo a informação, já possuem relação de identidade pelo objeto estudado, e são interdisciplinares. No futuro essa relação poderá ser intensificada.

\section{Abstract}

The changes happened in the current world are interfering in Library Science causing dynamism in the librarian's profession and the arise of the Information Science promotes the theoretical framework for the study of the information, making possible the relation between the practice and the theory. The information that in the past was made public orally or by books, it shows now in several ways, such as printed papers or electronics, and still in books, but also in newspapers, papers, video tapes, CD-ROM, DVD, among others, and the librarian works out between the information and its user, making easier the localization of the information, guaranteeing its access and promoting its use. The users of libraries and of the current information systems are different from the libraries readers from the past, especially in what concerns to the factor time: if in the past, the reader attended the library to read for long hours, in the present the user demands the information to read in others environment. In the study of Information Science, since the decade of 1940, many studious stand out like Vannevar Bush, Calvin Mooers, Mikhailov, Borko, Saracevic, Wersig, among others. The Information Science is devoted to scientific subjects and to the professional practice towards the problems of 
the effective communication of the knowledge and of its registrations among the human beings, in the social, institutional or individual context of the use and of the needs of information. For those studies, the technologies of information are essential. Library Science involves from the study of the user's profile, development of collections, until the promotion of the use of the information, embracing a long journey to be achieved by the librarian. Finally, the Information Science, the Library Science and others scientific chains that have the information as an object of study, already possess identity relations to the studied object, and they are interdisciplinary. In the future this relation can be intensified.

No decorrer dos últimos anos aconteceram mudanças significativas na profissão de bibliotecário em função de fatores como as novas demandas sociais por informação ou a possibilidade de usar modernas tecnologias para processá-la e disseminá-la. De um profissional passivo, o guardiāo, passou o bibliotecário a gestor de informação, terminologia esta que lhe atribui idéia de dinamismo, condizente com a sua atuação na sociedade contemporânea.

Persiste o objetivo de organizar o conhecimento, mas diante do aumento incessante de produção de informação surgem inúmeras possibilidades de realizar esse trabalho. A informação, que no passado circulava oralmente ou na forma de livros, apresenta-se agora em suportes diversos, tanto impressos quanto eletrônicos, sob forma de livros ainda, mas também como periódicos, papers, fitas de vídeo, CD-ROM, DVD, entre outros, e o bibliotecário exercita-se entre a informação e seu usuário, facilitando-lhe a localização, garantindo-lhe o acesso e promovendo o seu uso.

Os usuários das bibliotecas e dos sistemas de informação atuais diferem dos leitores das bibliotecas de alguns anos atrás, especialmente no que concerne ao fator tempo: se no passado, o leitor freqüentava a biblioteca para ler por horas seguidas, no presente o que se percebe é a urgência pela informação e a notável diminuição do tempo disponível para a leitura na biblioteca. Esse fato parece indicar, na literatura da área, a substituição do termo "leitor" pelo termo "usuário".

Para bem atender ao novo usuário, surge o novo profissional e os novos recursos tecnológicos de informação. A função do bibliotecário moderno exige habilidades no uso das tecnologias, a fim de proporcionar serviços mais eficientes. Também se percebe claramente nos tempos atuais a mudança estabelecida no próprio paradigma da Biblioteconomia, que se deslocou do acervo para o acesso: as possibilidades de prestar serviços à distância tornaram-se fato, por exemplo, quando o usuário consulta as bibliotecas virtuais. A Internet ampliou a visibilidade das bibliotecas, facilitando o seu uso sem necessidade da consulta presencial.

A base da atuação profissional do bibliotecário, a informação, que é também o seu objeto de estudo, tomou amplas proporçóes, desde a segunda metade do século XX, vindo a ser objeto de estudo de uma ciência pós-moderna, a Ciência da Informação. Esta é uma ciência autônoma, com estatuto próprio, e interdisciplinar por natureza. Originou-se no bojo da revolução científica e técnica, na década de quarenta, tendo seus conceitos sido estabelecidos na década de sessenta.

Em 1945, Vannevar Bush, cientista do Instituto de Tecnologia de Massachusetts (MIT) e chefe da equipe científica americana durante a Segunda Guerra Mundial, identificou o problema da "explosão da informação", ou seja, percebeu a necessidade de organizar as informaçóes a fim de proporcionar a sua recuperação. Chegou a idealizar uma máquina denominada MEMEX, que pode ser considerada precursora 
do computador. Vannevar Bush percebeu claramente o valor político e estratégico da informação e chegou a publicar suas idéias em artigo intitulado "As we may think" no periódico Atlantic Monthly (Pinheiro, 1997, p. 72).

O projeto de Bush náo foi adiante, mas muitos estudiosos do fenômeno da informação, através de conferências e artigos publicados, passaram a se envolver com essas questóes, como é o caso, ainda na segunda metade da década de quarenta do século passado, da publicaçáo dos trabalhos: "Cybernetics or control and communication in the animal and the machines", de Norbert Wiener e "The mathematical theory of communication", de Shannon e Weaver (Pinheiro, 1995, p. 42)

Não só os cientistas e engenheiros de todo o mundo, mas também os mais importantes governos e agências de financiamento, envolveram-se em programas estratégicos para controlar a explosão informacional, primeiro na ciência e tecnologia, e depois nos demais campos.

Em 1951, Calvin Mooers cunhou o termo "recuperação da informaçâo" para denominar o processo de busca de informaçóes, envolvendo os aspectos intelectuais da descrição de informaçóes e as demais especificidades dessa operação.

De acordo com Saracevic (1991), a recuperação da informação apresenta seus próprios e específicos problemas, dentre os quais destacam-se três que continuam fundamentais ainda hoje (p. 3)

- como descrever intelectualmente a informação?

- como especificar intelectualmente a busca?

- que sistemas, técnicas ou máquinas devem ser empregados?

A corrente soviética de estudiosos é representada por Mikhailov, diretor do VINIT, organização de Moscou, que denominou de Informatik o estudo da informação científica. Esse fato, de acordo com Gomes (1980, p. 7-8), trouxe uma certa ambigüidade na compreensão da Ciência da Informação por parte dos especialistas, e percebe-se que os bibliotecários e os documentalistas entendiam que se referia à Ciência da Informação, como a corrente russa, e os analistas de sistemas tinham o entendimento dos franceses, ou seja, como Informática. De acordo com Pinheiro (1997, p. 77) ao se analisar o conceito de Mikhailov, fica claro que ele se referia à Ciência da Informaçáo, apesar da denominação Informatik, em russo.

Em artigo intitulado "Information Science: what is it?", publicado no "American Documentation”, em 1968, Borko (1968, p. 3) expóe, sem grandes comprometimentos com respostas exatas, porém mais com o objetivo de suscitar questóes, sobre o que é Ciência da Informação e o que fazem os profissionais da área. É uma tentativa de esclarecer a natureza desse campo da ciência, no momento em que o American Documentation Institute (ADI) se transformou em American Society for Information Science (ASIS).

Esse autor chega a uma definição de Ciência da Informação a partir de uma síntese das idéias expostas nas três definiçóes de Robert S. Taylor, publicadas no Annual Review. Então, para Borko (1968)

Ciência da Informação é a disciplina que investiga as propriedades e o comportamento da informação, as forças que governam o fluxo da informação e os meios de processamento da informação para otimizar a acessibilidade e uso. Ela diz respeito àquele corpo do conhecimento relacionado com a origem, coleta, organização, armazenamento, recuperação, interpretação, transmissão, transformação e utilização da informação (p. 3). 
Isto inclui a investigação das representações da informação nos sistemas naturais e artificiais, o uso de códigos para transmissão eficiente de mensagens e o estudo dos recursos e técnicas de processamento da informação tais como computadores e seus sistemas de programação.

A Ciência da Informação, para Borko, é uma ciência interdisciplinar, derivada e relacionada com áreas como: matemática, lógica, lingüística, psicologia, tecnologias do computador, operação de pesquisa, artes gráficas, comunicação, biblioteconomia, administraçáo e outros campos similares. Ela possui componentes de ciência pura e de ciência aplicada, em cuja área vem desenvolvendo serviços e produtos.

Esta é uma definição que pretende ser abrangente, pois lida com um tema complexo e multidimensional.

Borko afirma que Biblioteconomia e Documentação são aspectos aplicados da Ciência da Informação e que deve haver parceria no sentido de bibliotecários e documentalistas se basearem nas teorias da Ciência da Informação, e esta estudar as técnicas e experiências dos bibliotecários e documentalistas. A Ciência da Informação se faz necessária porque tem como meta promover um corpo de informaçóes que guiam o aperfeiçoamento nas várias instituiçôes da sociedade, através de procedimentos dedicados à acumulação e transmissão de conhecimento.

Existem outros recursos utilizados com essa função, tais como: livros, escolas, bibliotecas, cinemas, periódicos, conferências, entre outros. Entretanto estes não são adequados às necessidades de comunicação da sociedade de hoje, por alguns fatores como: o grande crescimento em ciência e tecnologia e novos conhecimentos surgindo tornando os velhos obsoletos; a rapidez com que as técnicas de conhecimento vão ficando ultrapassadas; o aumento da especialização que torna muito difícil o intercâmbio e a comunicação da informação entre disciplinas; o grande número de trabalhos científicos e o grande número de periódicos técnico-científicos que existem hoje; o curto espaço de tempo que decorre entre a pesquisa e a aplicação, que exige uma informação mais precisa e imediata.

Ainda para o autor citado, o pesquisador pode investigar em nove categorias dentro da Ciência da Informação. São elas: necessidades e uso da informação; criação e reprodução da documentação; análise lingüística; tradução; resumo, classificação, codificação e indexação; planejamento de sistemas; análise e avaliação; padrôes de recognição, e sistemas adaptativos. O pesquisador pertence a uma classe pequena quantitativamente, mas com bastante perspectivas em produção. Borko afirma que não há, em Ciência da Informação, severas distinções entre pesquisa e tecnologia.

No sentido de atualizar ou redefinir uma ciência, após algumas décadas de sua instituição e, portanto, podendo dar um enfoque contemporâneo, Saracevic (1991, p. 5) afirma:

A Ciência da Informação é um campo dedicado às questôes científicas e à prática profissional voltadas para os problemas da efetiva comunicaçáo do conhecimento e de seus registros entre os seres humanos, no contexto social, institucional ou individual do uso e das necessidades de informação. No tratamento destas questóes são consideradas de particular interesse as vantagens das modernas tecnologias informacionais.

A respeito da natureza interdisciplinar dessa ciência, Saracevic argumenta que ela se fez e ainda assim permanece em decorrência de que os pioneiros possuíam formaçáo muito variada, havendo nesse grupo: engenheiros, bibliotecários, químicos, lingüistas, 
filósofos, psicólogos, matemáticos, cientistas da computação, homens de negócio e outros mais, vindos de diferentes profissóes ou ciências. Ainda que nem todos esses campos tenham influência efetiva, essa multiplicidade é um dado significante.

Em ensaio apresentado na Conferência Internacional sobre Concepçóes de Biblioteconomia e Ciência da Informação na Universidade de Tampère, Finlândia, em 1991, Saracevic enfoca as relaçôes interdisciplinares entre a Ciência da Informação e quatro campos: Biblioteconomia, Ciência da Computação, Ciência Cognitiva (incluindo Inteligência Artificial) e Comunicação.

Para estabelecer as relações da Ciência da Informação com a Biblioteconomia, Saracevic começa valorizando as atividades realizadas pelas bibliotecas e situando-as, não apenas como organizaçóes particulares ou como sistemas de informação, mas principalmente como instituiçóes sociais, culturais e educacionais. Faz uma citação de Jesse Shera que, em 1972, afirma acerca de bibliotecas:

[...]. contribuindo para o sistema total de comunicação na sociedade [...] Embora tenham as bibliotecas sido criadas como instrumentos para maximizar a utilização dos registros gráficos em benefício da sociedade, elas atingem sua meta trabalhando com os indivíduos e através deles, atingem a sociedade (Saracevic, 1991, p. 6).

As semelhanças entre Ciência da Informação e Biblioteconomia estão na preocupação com o social e na utilização dos registros gráficos; entretanto percebe-se, especialmente nas agendas de pesquisa e nos eventos científicos as diferenças existentes entre ambas com relação a: seleção dos problemas propostos e a forma de sua definiçãa, questóes teóricas, práticas, instrumentos e abordagens utilizados. A interdisciplinaridade da Ciência da Informação é uma característica que a distingue da Biblioteconomia de forma significativa. Saracevic conclui que Ciência da Informação e Biblioteconomia constituem campos diversos, embora relacionados.

Em relação à Ciência da Computação, que trata dos algoritmos que transformam informaçóes, a Ciência da Informação dela se diferencia porque trata da natureza mesma da informação e sua comunicação para uso pelos humanos. O que as relaciona é a aplicação dos computadores e da computação na recuperação da informação, assim como nos produtos, serviços e redes associados.

No que tange à Ciência Cognitiva, uma das ciências mais recentes, surgida na década de oitenta (1980), também interdisciplinar, e que tem como objetivo explicar como funciona a mente, o computador desempenha um importante papel, tanto como ferramenta quanto como fonte de modelagem e teste.

Dentro dessa ciência desenvolvem-se os conceitos de Inteligência Artificial. Essa Inteligência subdivide-se em Inteligência Artificial forte, na qual se estuda a parte teórica e Inteligência Artificial fraca, que abrange sistemas inteligentes que são muito utilizados em Ciência da Informação, e também hipertextos, bases de conhecimento, interfaces inteligentes, entre outros.

A informação, enquanto fenômeno, é estudada em Inteligência Artificial forte, uma vez que esta Inteligência é fonte do modelo teórico da cognição. Assim sendo, a Ciência da Informação pode realizar pesquisas básicas nessa área.

Para estabelecer relaçóes entre Ciência da Informação e Comunicação, Saracevic começa por expor as dificuldades existentes na compreensão da palavra comunicação. Existe confusão entre o processo de comunicação enquanto objeto de investigação e comunicação como nome do campo em que o processo é investigado, 
isto é, “a comunicação (campo) estuda a comunicação (processo)”. (SARACEVIC, 1991, p. 9)

Como há discussão no significado de comunicação e também no de informação, há debates e estudos acadêmicos variados sobre o assunto. Mas, de maneira geral, a compreensão acerca das relações entre Ciência da Informação e Comunicação, são apontadas, por Saracevic, como as relaçóes entre o fenômeno informação e o processo comunicação.

Já em 1993, Gernot Wersig, "professor do Departamento de Comunicação de uma Unidade de Trabalho em Ciência da Informação na Universidade de Berlim”, apresenta a Ciência da Informação sob um enfoque pós-moderno, considerando a mudança do papel do conhecimento na sociedade (Pinheiro, 1997, p. 157).

Juntamente com a Ecologia, a Ciência da Informação não é uma ciência clássica. Ela surge justamente pela necessidade de desenvolver estratégias para solucionar problemas causados pelas ciências clássicas e pelas tecnologias. (Wersig, 1993, p. 234)

Wersig (1993) chama a atenção para a mudança do papel do conhecimento que está ocorrendo para indivíduos, organizaçóes e sociedades, segundo ele, desde aproximadamente a década de sessenta (1960).

Esta mudança é evolutiva e tem, pelo menos duas dimensóes - uma filosófica e outra tecnológica [...] Também há que se considerar relevante, pelo menos quatro traços dessa questão:

- despersonalização do conhecimento: tecnologia da comunicação;

- veracidade do conhecimento: tecnologia da observação;

- fragmentação do conhecimento: tecnologia da apresentação, e

- racionalização do conhecimento: tecnologia de informação (p. 230).

Para Wersig (1993, p. 238), a Ciência da Informação não possui uma teoria, mas uma estrutura de amplos conceitos científicos ou modelos e pode desenvolver algum tipo de sistema de navegação conceitual, que seria uma abordagem teórica pós-moderna. Desde 1975, em artigo publicado com Nevelling \& Wersig (1975, p. 134) já afirmava que a responsabilidade social parece ser a real preocupação que movimenta a Ciência da Informação.

Ainda nesse aspecto da Ciência da Informação e sua preocupação com o social, temos Pinheiro (1999) que afirma ter observado, nos resultados de pesquisa desenvolvida em tese de doutorado, que:

a tendência inicial de privilegiar aspectos tecnológicos, a máquina pela máquina, foi se diluindo, ou numa metáfora com a terminologia da área, o 'hard' foi se tornando 'soft', e as disciplinas originária e fortemente tecnológicas passaram a ser estudadas em função dos seus impactos na sociedade e na relação com o homem, na tentativa de um diálogo amigável, busca de interfaces e quebra de arestas (p. 178).

Está pois a Ciência da Informação hoje, juntamente com outras ciências e com a utilização da tecnologia, buscando propiciar a utilização do conhecimento em prol de melhores condiçóes de vida para a humanidade. Nesse sentido Pinheiro (1999) ainda diz que a Ciência da Informação caminha, "juntamente com a Comunicação e outros campos do conhecimento contemporâneos, para a constituição de uma nova categoria de ciências sociais - as ciências tecno-culturais" (p. 178).

Isto posto, voltemos ao início: Biblioteconomia ou Ciência da Informação? Pergunta que, entendo, deve ser assim respondida: Biblioteconomia e Ciência da Informação. 
A Biblioteconomia já existia na Antiguidade Clássica, quando as bibliotecas centralizavam a cultura das grandes civilizaçôes e os bibliotecários já se faziam representar diante dos papiros egípcios, na Biblioteca de Alexandria ou dos tijolos de argila da Biblioteca do rei Assurbanipal, em Nínive.

Por toda a história da civilização vem a profissão de bibliotecário superando as dificuldades, vencendo os desafios das mudanças ocorridas, observáveis nos vários suportes da informaçáo: tijolos de argila, papiro, pergaminho, papel, códex, livro impresso, periódico e, finalmente, o documento eletrônico em suas diversas modalidades. Transformou-se a profissão de bibliotecário sempre diante das novas demandas sociais estabelecidas. Tanto cresceu o valor estratégico da informação que se estabeleceu a Ciência da Informação, não havendo, entretanto, razão para a Biblioteconomia deixar de existir.

Dentre os diversos tipos de bibliotecas existentes, como as escolares, as universitárias, as nacionais, as especializadas, todas com produtos e serviços direcionados a um determinado usuário, destacamos a biblioteca pública, por sua abrangência, pois objetiva atender a todos os usuários em qualquer demanda de informação.

O objetivo grandioso da biblioteca pública, juntamente com outros fatores, talvez tenha dificultado o êxito dessa instituição por todos esses anos. O bibliotecário brasileiro Rubens Borba de Moraes, já apontava desde 1943, em relação à profissão do bibliotecário, que a preocupação técnica e única é tão prejudicial quanto a sua falta - dizia ele que o bibliotecário moderno deve ser um misto de técnico e intelectual. (Moraes, 1983, p.22)

Hoje já temos os estudos de perfil do usuário, estudos de demanda de informação que possibilitam o planejamento do serviço bibliotecário, especialmente em bibliotecas públicas, a fim de aperfeiçoar o atendimento a determinadas categorias de usuários e em algumas situaçôes, motivar usuários potenciais a frequentar as bibliotecas.

No processo de modernização que a Biblioteconomia vem desenvolvendo quanto ao conhecimento, habilidades tecnológicas e nova atitude profissional frente ao usuário, talvez haja necessidade de estabelecer uma nova marca, ou seja, um novo nome. Quando se interroga pessoas da sociedade acerca das atividades do bibliotecário, percebe-se o descompasso existente entre as respostas dadas e a atual realidade da profissão. De acordo com Hayes, citado por Barbosa (1998)

Os nomes das profissóes refletem o que seus profissionais fazem. Por exemplo, os administradores gerenciam organizaçóes, os psicólogos lidam com o comportamento humano, os sociólogos analisam aspectos da sociedade. E o bibliotecário faz o quê? Lida com livros em bibliotecas? Claro que esta visão não mais reflete o que vem ocorrendo dentro das bibliotecas e menos ainda o que se desenvolve em outros domínios da informação. Sem dúvida, biblioteca e bibliotecário são termos que se tornaram mais amplos e não mais se referem exclusivamente a um edifício que guarda livros ou ao profissional que trabalha dentro dele (p. 54).

Poderíamos então sugerir uma maior reflexão e a realização de estudos acerca de uma denominação mais fiel para a atuação deste profissional da informação e da sua área de formaçáo, ou seja, para o bibliotecário e para a Biblioteconomia. Entretanto existem outros fatores a serem observados, entre os quais a relevância do nome BIBLIOTECA que, etimologicamente origina-se dos vocábulos gregos biblion, livro, e théke, caixa (Fonseca, 1992, p. 59). 
O uso contínuo da palavra biblioteca desde a antiguidade, atribuiu valores culturais significativos ao termo, a ponto de ser absolutamente aceito e reconhecido pela sociedade, quer no meio científico, cultural, quer de um modo geral, nas diversas comunidades. Esse reconhecimento do nome, fator positivo para qualquer empreendimento, incentiva o seu uso por outros setores, como já vem ocorrendo, especialmente na utilização do vocábulo teca, como nos exemplos que seguem:

- Palinoteca: acervo de grãos de pólen;

- Carpoteca: coleção de frutos;

- Xiloteca: reunião de exemplares de madeira catalogados (Maués, 2003).

Também observamos na internet a denominação Biblioteca sendo utilizada em vários sites genéricos, para referir informaçôes disponíveis referentes aos possíveis interesses de seus visitantes.

Um caso interessante a destacar é o de uma biblioteca especializada em reciclagem que utiliza o nome RECICLOTECA. A recicloteca constitui-se em um Centro de Informaçóes sobre Reciclagem e Meio Ambiente, cujo endereço eletrônico é: < http:// www. recicloteca.org.br>.

Enfim, biblioteca como "assembléia de usuários da informação", conceito este proposto pelo professor Edson Nery da Fonseca (1992, p. 60), envolve desde o estudo do perfil do usuário, desenvolvimento de coleçóes, até a promoção do uso da informação, o que abrange um longo caminho a ser percorrido pelo profissional bibliotecário.

Assim sendo, talvez a atitude mais coerente relativa ao nome do campo do conhecimento e ao seu profissional, seja a permanência da denominaçáo tradicional e a utilização de marketing sobre o novo perfil do bibliotecário, divulgando para a sociedade o profissional dinâmico que é hoje o bibliotecário, habilitado na mediação da informação com o uso das mais modernas tecnologias disponíveis no mercado.

E finalmente observamos que Ciência da Informação, Biblioteconomia e demais correntes científicas que têm como objeto de estudo a informação, já possuem relação de identidade pelo objeto estudado, e são interdisciplinares. No futuro essa relação poderá ser intensificada.

\section{Referências bibliográficas}

Barbosa, R. R. (1998). Perspectivas profissionais e educacionais em Biblioteconomia e Ciência da Informação. Ciência da Informaçáo, Brasília, v.27, n.1, p. 53 - 60.

Borko, H (1968). Information Science: What is it? American Documentation. v. 19, n. 3/5. Fonseca, E. N. (1992). Introduçáo à Biblioteconomia. São Paulo: Pioneira.

Gomes, H. E. (1980). Apresentação. In: Ciência da Informaçáo ou Informática? Rio de Janeiro: Calunga.

Maués, E. (2003). Xiloteca do Goeldi ganha exposição virtual. O Liberal, Belém, 13 abr., Atualidades, p. 7.

Moraes, R. B. (1983). O problema das bibliotecas brasileiras. 2. ed. Brasília: Associação dos Bibliotecários do Distrito Federal. 
Pinheiro, L. V. R. (1997). A Ciência da Informaçáo entre sombra e luz: domínio epistemológico e campo interdisciplinar. 1997. 278 f. Tese (Doutorado em Comunicação e Cultura) - UFRJ / ECO, Rio de Janeiro.

Pinheiro, L. V. R. (1999). Campo interdisciplinar da Ciência da Informação: fronteiras remotas e recentes. In: PINHEIRO, L. V. R. (Org). Ciência da Informaçáo, Ciências Sociais e interdisciplinaridade. Brasília, Rio de Janeiro: Instituto Brasileiro de Informação em Ciência e Tecnologia.

Pinheiro, L. V. R. \& Loureiro, J. M. M. (1995). Traçados e limites da Ciência da Informação. Ciência da Informação, Brasília, v. 24, n. 1, jan. / abril.

Recicloteca (2009). Centro de Informaçóes sobre Reciclagem e Meio Ambiente. Recuperado em 10 julho, 2009, do http://www.recicloteca.org.br.

Saracevic, T. (1991). Information Science: origin, evolution and relations. Pré-print.

Wersig, G. (1993). Information Science: the study of postmodern knowledge usage. Information Processing \& Management, v. 29, n. 2, p. 229-239.

Wersig, G. \& Nevelling, U. (1975). The phenomena of interest to Information Science. The Information Scientist, v. 9, n. 4, Dec. 